\title{
Carotid Web: Under-Recognized Etiology for Ischemic Stroke
}

\author{
Hong-Kyun Park, Keun-Sik Hong \\ Department of Neurology, Inje University Ilsan Paik Hospital, Goyang, Korea
}

Carotid web (CA-Web) is defined as a rare form of focal intimal fibromuscular dysplasia, which is protruded into the lumen and forms a membrane-like shelf in the posterior aspect of the internal carotid artery (ICA) bulb. It could lead to flow stagnation and thrombus formation in the proximal ICA, and has been increasingly recognized as a potential source of thromboembolism in young patients with recurrent cerebral ischemic events in the anterior circulation of an undetermined cause. In the general population, the prevalence of CA-Web is unknown and it is rarely found among stroke patients. However, CA-Webs are more frequent among young patients with cryptogenic ischemic stroke. Despite antiplatelet therapies, these patients appear to have a higher risk of recurrent ischemic stroke. As alternatives, anticoagulation, surgical resection, and carotid artery stenting are being considered, but largely based on anecdotal evidence.

J Neurosonol Neuroimag 201\$;10(2):100-105

Key Words: Carotid web; Carotid artery diseases; Cerebral infarction; Fibromuscular dysplasia

Received: November 30, 2018 Revised: December 11, 2018 Accepted: December 11, 2018

Address for correspondence: Keun-Sik Hong

Department of Neurology, Inje University Ilsan Paik Hospital, 170 Juhwa-ro, Ilsanseo-gu, Goyang 10380, Korea Tel.: +82-31-910-7680 Fax: $+82-31-910-7368$ E-mail: nrhks@paik.ac.kr

\section{HISTORY AND DEFINITION}

Carotid web (CA-Web) is now recognized as a rare form of carotid intimal variant fibromuscular dysplasia (FMD). The first angiographic description of the proximal internal carotid artery (ICA) involvement of FMD appeared in the addendum section of a case report by Palubinskas and Ripley in 1964. However, the authors did not report whether the patient had cerebral ischemic events. ${ }^{1}$ In 1965 , the first symptomatic case with pathological confirmation of FMD involving the ICA was reported, but the angiographic findings did not show typical features of CA-Web, and the histological findings were compatible with the medial subtype of FMD, not the intimal subtype. ${ }^{2}$

In 1968, the first case of symptomatic CA-Web was reported in a 30-year-old woman with transient right hemiparesis. The angiography showed a discrete ridge in the posterior wall of the proximal ICA and the pathologic findings were compatible with the intimal type of FMD, which are typical features of CA-Web. However, the authors did not use the term of 'carotid web'. ${ }^{3}$ In 1973, the term first appeared as 'web formation' to describe the angiographic finding of four cases with weblike tissue in the lumen of the proximal ICA, but all the cases were asymptomatic. ${ }^{4}$ Since then, this lesion has been described as carotid web, web-like formation, ${ }^{4}$ web-like septum, ${ }^{5}$ diaphragm, ${ }^{6}$ spur, ${ }^{7}$ carotid bulb atypical FMD, ${ }^{7}$ shelf, ${ }^{8}$ or pseudovalvular fold. ${ }^{9}$ The second pathologically proven symptomatic CA-Web case was additionally reported in $1979,{ }^{10}$ and then the following case reports, case-control studies, and reviews have highlighted CA-Web as an under-recognized cause in young patients with cryptogenic ischemic stroke., ${ }^{7,11-20}$

\section{HISTOPATHOLOGY}

The histological classification system for FMD, established in 1971 from a consensus conference between the Cleveland Clinic and the Mayo Clinic, ${ }^{21,22}$ is based on the arterial layer involvement. ${ }^{23}$ Medial type of FMD 
is most common, accounting for $>90 \%,{ }^{24}$ and is characterized histologically by the media thickening due to hyperplasia of fibrous tissue and smooth muscle and angiographically by multifocal "string of beads" appearance. Intimal type (1-2\%, or up to $5 \%$ of carotid FMD) has pathological features of intimal thickening and disruption/fragmentation of internal elastic lamina and angiographical characteristics of unifocal $(<1 \mathrm{~cm})$ or tubular $(\geq 1 \mathrm{~cm})$ appearances. CA-Web is thought to be one type of intimal FMD because histopathologic studies of surgical resections have revealed the abnormalities in the intimal layer of the arterial wall.,7,19,25 Adventitial type, fibrous dysplasia limited in the adventitial wall, is the most rare form (<1\%) of FMD, and is less well detected by angiographic studies providing images of the arterial lumen only.

\section{EPIDEMIOLOGY}

The prevalence of CA-Web in the general population has not been studied. In an earlier studies analyzing 7,000 carotid angiograms conducted in a single center for 8 years between late 1960s and early 1970s, CA-Web was detected in only four cases ( $0.6 \%$ of cases with carotid angiogram), and it accounted for $2.9 \%$ of 140 cases with non-atheromatous stenosis or occlusion of the ICA and its major branches. ${ }^{4}$ In a recent study which retrospectively assessed CT angiograms of 576 patients, CA-Web was detected in seven cases (1.2\%; 95\% confidence intervals [CI], 0.4-2.5\%), and two of the seven patients had acute ischemic stroke, possibly related to CA-Web. ${ }^{12}$ Among patients treated with endovascular thrombectmy, the MR CLEAN (Multicenter Randomized Clinical Trial of Endovascular Treatment for Acute Ischemic Stroke in the Netherlands) investigators reported that CA-Webs were found in $13(2.9 \%)$ out of 443 patients with available carotid bifurcation; 11 (2.5\%) in the symptomatic side and two (0.5\%) in the asymptomatic side. ${ }^{17}$ However, in patients with cryptogenic stroke, CA-Webs were more frequently found, ranging in $9.4 \%$ to $37 \%$ of these patients. .,12,14-16,18,20 $^{2}$

Case-control studies have shown that CA-Web is associated with an increased risk of ipsilateral carotid territory ischemic stroke. In a population-based case-control study of Afro-Caribbean population, CA-Web was associated with a 9-fold increased risk of carotid territory ischemic stroke after adjustment for other major vascular risk factors (adjusted odds ratio [OR], 9.45 [95\% CI, 1.71-52.21]; $p=0.009$ ). When restricted in patients with cryptogenic ischemic stroke, the association was much greater (adjusted OR, 24.06 [95\% CI, 1.78-325.63]; $p=0.016)$. Another hospital-based case-control study showed that the prevalence of CA-Web in patients aged $<60$ who experienced anterior circulation cryptogenic ischemic stroke was 8-fold higher compared to ageand sex-matched patients with cerebral aneurysms, arteriovenous malformations, or primary intracerebral hemorrhages (9.4\% vs. 1.0\%; OR, 8.0 [95\% CI, 1.2-67]; $p=0.032) .{ }^{14}$ Therefore, CA-Web appears to be a significant risk factor in young patients with cryptogenic ischemic stroke.

In two recent studies with more than 20 cases of symptomatic CA-Webs, the mean or median age was 46 and 51, and the median National Institutes of Health Stroke Scale score was 10.5 (interquartile range, 3.0-16.0) and 7.0 (2.0-15.0). ${ }^{14,15}$ Therefore, patients with symptomatic CA-Web are much younger and likely to have more severe strokes compared to overall ischemic stroke patients. For sex preponderance, about $90 \%$ of patients with classic FMD are women. However, the female predominance is likely lower in CA-Web than in classic FMD. When data combined from earlies cases, about $65 \%$ of CA-Web cases were female. ${ }^{19}$ However, in a recent studies, the proportion of female was $43 \%$ ( 23 out of 53 cases $){ }^{14}$

In these studies, time to recurrent ischemic event ranged a median of 9 to 13 months. ${ }^{7,2215}$ However, there is limited information about the epidemiology and the absolute risk of the carotid web.

\section{IMAGING STUDIES}

Conventional catheter-based digital subtraction angiography (DSA) has been the gold standard for the diagnosis of CA-Web. Recently, literature reported the usefulness of advanced non-invasive vascular imaging modalities although systematic analysis of their diagnostic yields compared to conventional angiography is limited. ${ }^{26}$ However, the non-invasive imaging studies frequently provide reliable findings of CA-Web, which 
clinicians should be aware of.

\section{Computed tomographic angiography (CTA)}

CTA seems to be the most widely used non-invasive imaging method for the diagnosis of CA-Web in recent years. ${ }^{72-14} \mathrm{CA}-\mathrm{Webs}$ are usually seen as a thin, smooth, membrane-like intraluminal filling defect along the posterior wall of the ICA bulb on oblique sagittal images (Fig. 1A, B), and axial source images show a corresponding thin septum. ${ }^{12,14}$ In a recent study, the correlation between CTA and conventional DSA for the diagnosis of CA-Web was high $(\kappa=0.92, p<0.0001) .{ }^{26}$ However, because of the angle-dependent visualization (Fig. $1 \mathrm{C}$ ), multiplane imaging reconstruction with careful review of images should be conducted. In addition, information on blood flow dynamic is usually not obtainable with CTA.

\section{Magnetic resonance angiography}

Data on the diagnostic accuracy of magnetic resonance (MR) angiography for detecting CA-Webs are limited. MR angiography can visualize the carotid web and has advantage of providing additional information of wall morphology and composition. However, a widely used, routine protocol of the time-of-flight sequence with 2-dimentional acquisition is less sensitive to slow and retrograde flow, and thereby has a disadvantage of delineating CA-Webs. In a small study of five patients, advanced techniques of 3-dimentional contrast MR angiography and multi-contrast fast spine echo image could yield a higher diagnostic accuracy. ${ }^{27}$ The 3-dimentional contrast MR angiography well visualized CA-Webs protruded in the lumen, and proton density-weighted fast spin echo images showed thickening and enhancement of arterial wall. In addition, the pre-contrast T1-weighted images, which showed no signal loss indicating lipid core within the vessel wall, were useful to differentiate CA-Webs from atherosclerotic plaques, and the post-contrast $\mathrm{T} 1$-weighted images showed residual contrast-enhanced blood accumulation in the CA-Webs, adding additional diagnostic information. Therefore, when radiation hazard should be minimized, advanced MR techniques would be preferred to CTA or conventional DSA .
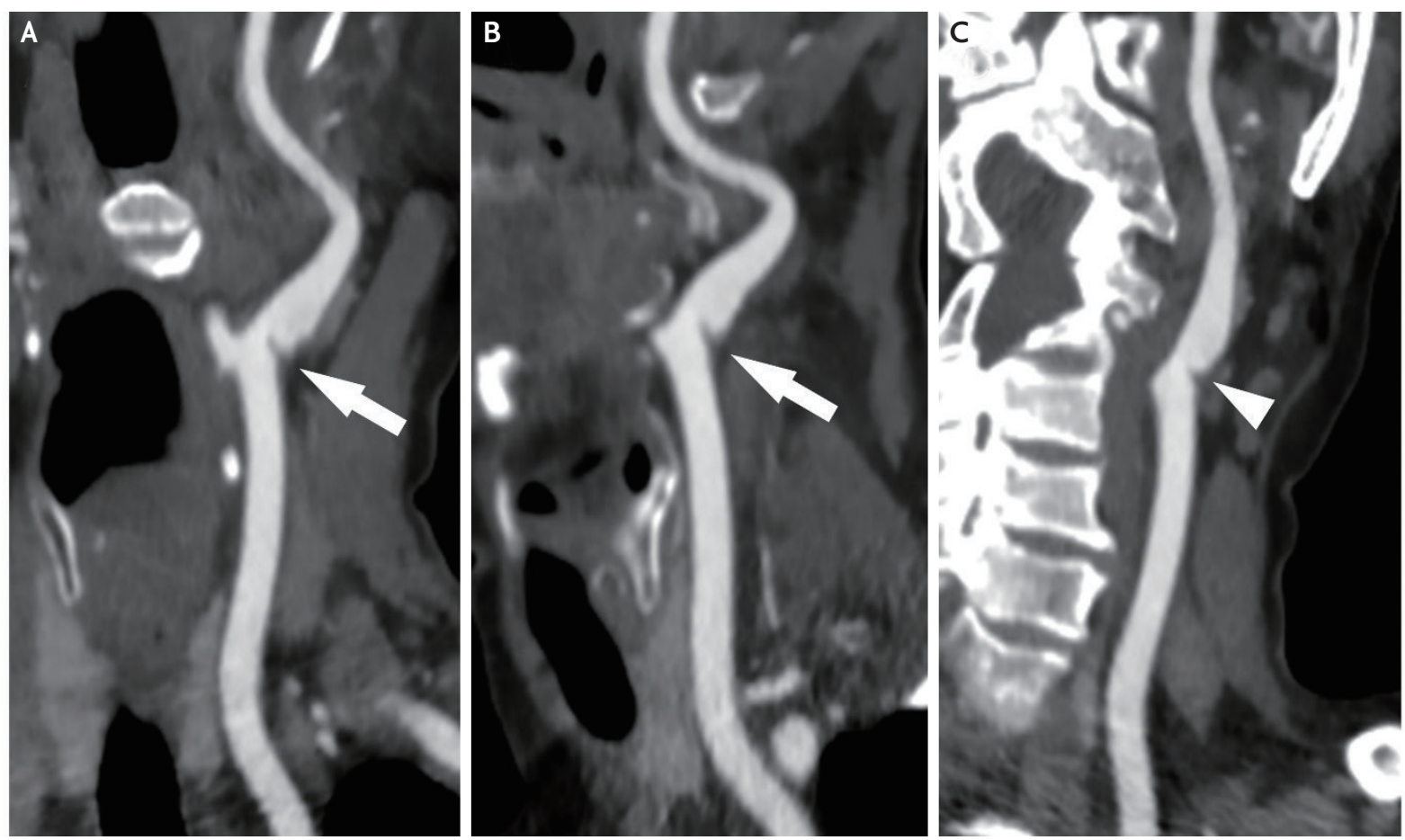

FIG. 1. Identification of carotid web according to the angle on computed tomographic angiography. Computed tomographic angiography of the carotid artery depicts a sharp membrane-like shelf of the carotid web (arrows in A and B) and an attenuated intraluminal protrusion according to cut (arrowhead in C). 


\section{Ultrasonography}

In 1991, the first case report of ultrasonographic findings of CA-Web showed a heterogeneous moderately echogenic wedge-shaped band protruding into the arterial lumen. ${ }^{11}$ Ultrasonography (US) would be the most simple and easily accessible imaging modality. However, US frequently provides non-specific findings such as mild bulbar-shaped protrusions, which could be misinterpreted as fibrous plaques of atherosclerotic origin.? In a comparative study, US had a less diagnostic accuracy compared to CTA and conventional DSA. ${ }^{26}$ However, experienced sonographers who are well educated about and familiar with CA-Web might more accurately and more easily detect this carotid lesion. Contrast-enhanced US, which is likely to better identify and assess arterial wall irregularities and plaque vulnerability in carotid atherosclerosis, might enhance the visualization of slit-like protrusion of CA-Web, not detected with conventional US (Fig. 2). However, there has been no validation study.
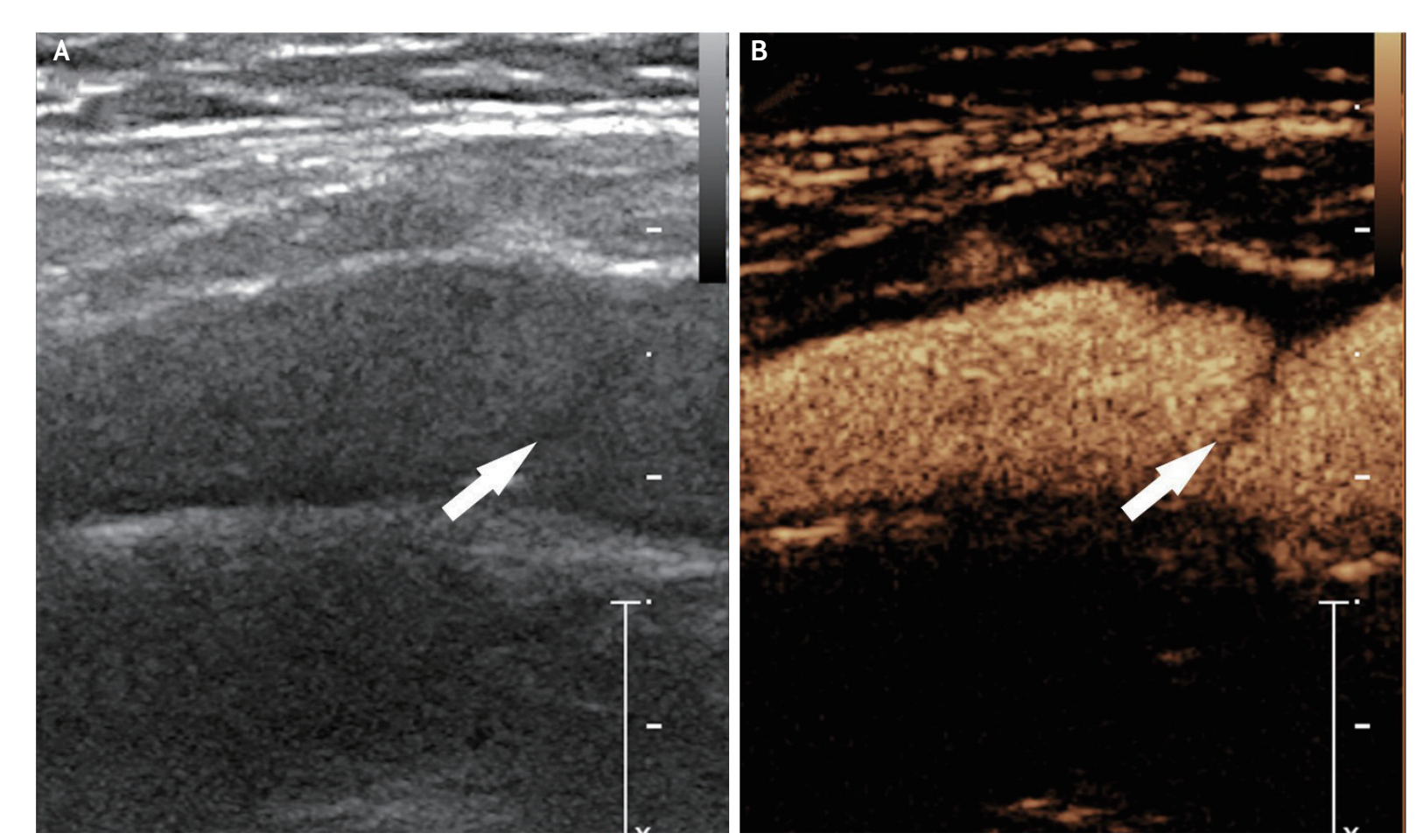

Fig. 2. Ultrasonographic evaluation of carotid web using the conventional and contrast-enhanced methods. (A) No specific abnormal findings were detected on the left proximal internal carotid artery during the conventional ultrasonographical evaluation (arrow). (B) Contrast-enhanced ultrasonography demonstrates a sharp intraluminal projection of the carotid web (arrow). The base of the carotid web shows a smooth contour arising from the arterial wall.

\section{Conventional digital subtraction angiography}

Conventional DSA has been generally considered as a gold standard diagnostic tool for carotid artery evaluation. In addition to visualizing carotid web, DSA is able to directly assess the presence of thrombus. Furthermore, the late venous phase images could evaluate the reflux and stasis of blood flow in the pocket of CA-Web (Fig. 3). Theoretically, thrombus might be produced from the static and turbulent blood flow in the carotid web pocket, and could be a potential embolic source of ischemic stroke. ${ }^{12,14}$ In a prospective registry study enrolling consecutive patients aged $<65$ with cryptogenic ischemic stroke, $29 \%$ of patients with CA-Web had superimposed thrombus. ${ }^{15}$

\section{TREATMENT}

Because of the lower prevalence and limited data on natural course, optimal secondary stroke prevention strategies based on sufficient evidence remain 


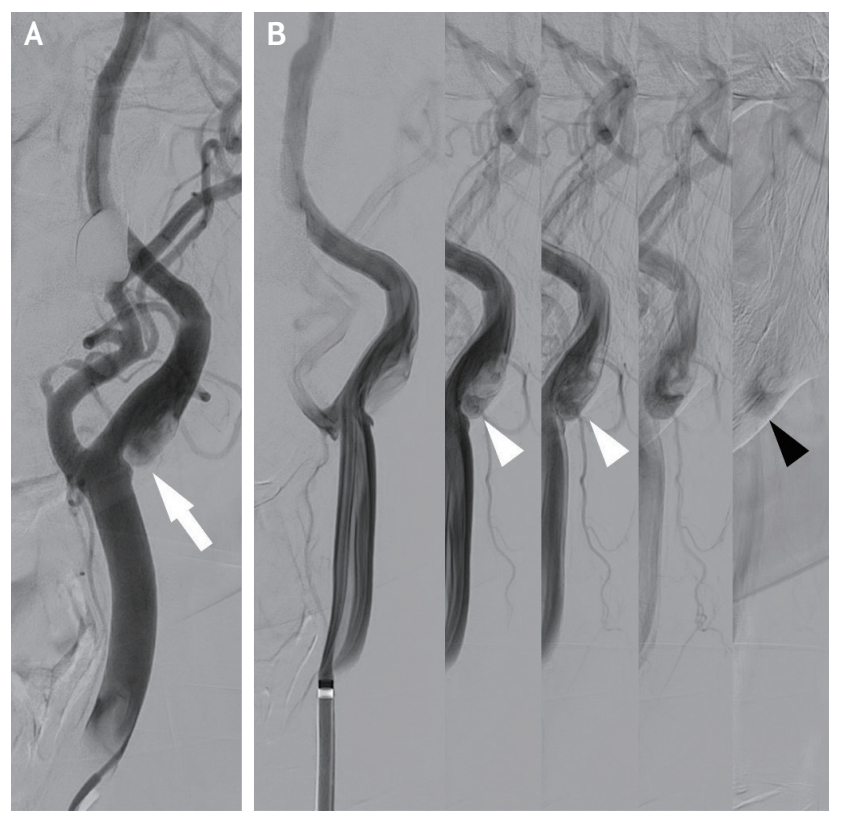

FIG. 3. Conventional digital subtraction angiographic evaluation of the carotid web. (A) Carotid web and pocket (arrow). (B) Delayed reflux of blood flow (white arrowheads), and contrast stagnation in the late venous phase of arterial angiography (black arrowhead) in the carotid web pocket.

unknown, and treatments reported have been only anecdotal. Given that 1 ) blood flow is stagnated and thrombus is produced around CA-Webs and 2) CA-Web is a developmental fibrotic tissue without regression, patients who experienced CA-Web related cerebral ischemic events would require long-term secondary stroke prevention therapies.

However, the risk of recurrent ischemic stroke is likely high with antiplatelet therapies. Among 20 patients treated with antiplatelet monotherapy, seven (30\%) had recurrent ischemic events in the vascular territory of CA-Webs during a mean follow-up 25 months, and the estimated risk of recurrent stroke was $20.0 \%$ at 1 year, $27.3 \%$ at 2 years, and $36.4 \%$ at 3 years. ${ }^{7}$ In another study of 24 patients, seven (29\%) had recurrent ischemic stroke (six patients) or transient ischemic attack (one patient) in the previous symptomatic CA-Web territory during a median follow-up of 10.7 months. Of the seven patients, two were on dual antiplatelet therapy, three on antiplatelet monotherapy, and two without antithrombotics. $^{15}$

Anticoagulation could be an alternative option of medical therapy, given the role of blood stasis in CAWebs for thrombus development. Choi et al. ${ }^{12}$ described one case in whom thrombus evolved during antiplatelet therapy, but resolved with anticoagulation. However, the benefit-to-risk ratio of long-term anticoagulation is unknown.

Surgical resection could be considered, particularly for patients with medical treatment failure. Among seven patients (two with recurrent ischemic events and five with a single event) who received surgical treatments, no patient experienced perioperative complications and there was no recurrent ischemic event during a median follow-up of 14 months. ${ }^{7}$ Carotid artery stenting could an alternative option to surgical resection. In a recent study of 16 patients who were treated with carotid artery stenting for recent symptomatic CA-Webs, there was no periprocedural complications, and no patients had recurrent ischemic strokes or transient ischemic attacks during a median follow-up of 4 months. ${ }^{15}$ Multicenter observational study also reported that 24 patients treated with carotid stenting had neither periprocedural events and nor additional cerebral ischemic event for a median of 12 months. In addition, among 23 patients with available follow-up US or CTA studies at a median of 10 months, no stenosis was detected. ${ }^{18}$

\section{CONCLUSION}

CA-Web is a rare form of intimal FMD. Recent studies indicate that it could be an important etiology in young patients with cryptogenic ischemic stroke, but has long been under-recognized. Stroke physicians should have knowledge of the key imaging findings and consider CA-Web as one of possible etiologies in cryptogenic ischemic stroke. More data, preferably from large multicenter registry studies, should be accumulated on the prognosis of symptomatic CA-Web and the factors associated with an increased risk of recurrent ischemic stroke related to CA-Web. The outcomes with medical, surgical, and neurointerventional treatments should be systematically captured and compared.

\section{Acknowledgments}

We appreciate Professor Cheolkyu Jung and Dr. Jun Yup Kim for providing original images of the carotid web. 


\section{REFERENCES}

1. Palubinskas AJ, Ripley HR. Fibromuscular hyperplasia in extrarenal arteries. Radiology. 1964;82:451-455.

2. Connett MC, Lansche JM. Fibromuscular hyperplasia of the internal carotid artery: report of a case. Ann Surg. 1965;162:59-62.

3. Rainer WG, Cramer GG, Newby JP, Clarke JP. Fibromuscular hyperplasia of the carotid artery causing positional cerebral ischemia. Ann Surg. 1968;167:444-446.

4. Momose KJ, New PF. Non-atheromatous stenosis and occlusion of the internal carotid artery and its main branches. Am J Roentgenol Radium Ther Nucl Med. 1973;118:550-566.

5. Osborn AG, Anderson RE. Angiographic spectrum of cervical and intracranial fibromuscular dysplasia. Stroke. 1977;8:617-626.

6. Lipchik EO, DeWeese JA, Schenk EA, Lim GH. Diaphragm-like obstructions of the human arterial tree. Radiology. 1974;113:43-46.

7. Joux J, Chausson N, Jeannin S, Saint-Vil M, Mejdoubi M, Hennequin JL, et al. Carotid-bulb atypical fibromuscular dysplasia in young Afro-Caribbean patients with stroke. Stroke. 2014;45:3711-3713.

8. Morgenlander JC, Goldstein LB. Recurrent transient ischemic attacks and stroke in association with an internal carotid artery web. Stroke. 1991;22:94-98.

9. Gironell A, Martí-Fabregas J, de Juan-Delago M, Lloret D, Fernandez-Villa JM, Martí-Vilalta JL. Carotid pseudo-valvular fold: a probable cause of ischaemic stroke. J Neurol. 1995;242:351-353.

10. So EL, Toole JF, Moody DM, Challa VR. Cerebral embolism from septal fibromuscular dysplasia of the common carotid artery. Ann Neurol. 1979;6:75-78.

11. Kliewer MA, Carroll BA. Ultrasound case of the day. Internal carotid artery web (atypical fibromuscular dysplasia). Radiographics. 1991;11:504-505.

12. Choi PM, Singh D, Trivedi A, Qazi E, George D, Wong J, et al. Carotid webs and recurrent ischemic strokes in the era of ct angiography. AJNR Am J Neuroradiol. 2015;36:2134-2139.

13. Joux J, Boulanger M, Jeannin S, Chausson N, Hennequin JL, Molinié V, et al. Association between carotid bulb diaphragm and ischemic stroke in young Afro-Caribbean patients: a population-based case-control study. Stroke. 2016;47:2641-2644.

14. Coutinho JM, Derkatch S, Potvin AR, Tomlinson G, Casaubon LK, Silver FL, et al. Carotid artery web and ischemic stroke: a case-control study. Neurology. 2017;88:65-69.

15. Haussen DC, Grossberg JA, Bouslama M, Pradilla G, Belagaje S, Bianchi N, et al. Carotid web (intimal fibromuscular dysplasia) has high stroke recurrence risk and is amenable to stenting. Stroke. 2017;48:3134-3137.

16. Sajedi PI, Gonzalez JN, Cronin CA, Kouo T, Steven A, Zhuo J, et al. Carotid bulb webs as a cause of "cryptogenic" ischemic stroke. AJNR Am J Neuroradiol. 2017;38:1399-1404.

17. Compagne KCJ, van Es A, Berkhemer OA, Borst J, Roos Y, van Oostenbrugge RJ, et al. Prevalence of carotid web in patients with acute intracranial stroke due to intracranial large vessel occlusion. Radiology. 2018;286:1000-1007.

18. Haussen DC, Grossberg JA, Koch S, Malik A, Yavagal D, Gory B, et al. Multicenter experience with stenting for symptomatic carotid web. Interv Neurol. 2018;7:413-418.

19. Kim SJ, Nogueira RG, Haussen DC. Current understanding and gaps in research of carotid webs in ischemic strokes: a review. JAMA Neurol. 2018 Nov 5 [Epub]. https://doi. org/10.1001/jamaneurol.2018.3366.

20. Sajedi P, Chelala L, Nunez-Gonalez J, Cronin C, Kittner S, Zhuo J, et al. Carotid webs and ischemic stroke: experiences in a comprehensive stroke center. J Neuroradiol. 2018 Sep 28 [Epub]. https://doi.org/10.1016/j.neurad.2018.09.003.

21. McCormack LJ, Poutasse EF, Meaney TF, Noto TJ Jr, Dustan HP. A pathologic-arteriographic correlation of renal arterial disease. Am Heart J. 1966;72:188-198.

22. Harrison EG Jr, Hunt JC, Bernatz PE. Morphology of fibromuscular dysplasia of the renal artery in renovascular hypertension. Am J Med. 1967;43:97-112.

23. Olin JW, Gornik HL, Bacharach JM, Biller J, Fine LJ, Gray BH, et al. Fibromuscular dysplasia: state of the science and critical unanswered questions: a scientific statement from the American Heart Association. Circulation. 2014;129:1048-1078.

24. Olin JW, Froehlich J, Gu X, Bacharach JM, Eagle K, Gray BH, et al. The united states registry for fibromuscular dysplasia: results in the first 447 patients. Circulation. 2012;125:31823190.

25. Touzé E, Oppenheim C, Trystram D, Nokam G, Pasquini $\mathrm{M}$, Alamowitch S, et al. Fibromuscular dysplasia of cervical and intracranial arteries. Int J Stroke. 2010;5:296-305.

26. Madaelil T, Nogueira R, Grossberg J, Anderson A, Barreira C, Haussen D. E-o64 carotid webs: a multimodality imaging study. J Neurointerv Surg. 2018;10:A80-A81.

27. Boesen ME, Eswaradass PV, Singh D, Mitha AP, Goyal M, Frayne R, et al. MR imaging of carotid webs. Neuroradiology. 2017;59:361-365. 